\title{
Configurações
}

Revista de sociologia

$24 \mid 2019$

Imaginar "futuros" do trabalho, contextos e vivências subjetivas

\section{Introdução - Imaginar "futuros" do trabalho, contextos e vivências subjetivas}

Ana Paula Marques, Miguel Chaves, Helena Serra e Paula Urze

\section{(2) OpenEdition \\ Journals}

Edição electrónica

URL: http://journals.openedition.org/configuracoes/7620

DOI: $10.4000 /$ configuracoes. 7620

ISSN: 2182-7419

\section{Editora}

Centro de Investigação em Ciências Sociais

Edição impressa

Paginação: 5-10

ISSN: 1646-5075

\section{Refêrencia eletrónica}

Ana Paula Marques, Miguel Chaves, Helena Serra e Paula Urze, "Introdução - Imaginar "futuros" do trabalho, contextos e vivências subjetivas », Configurações [Online], 24 | 2019, posto online no dia 18 dezembro 2019, consultado o 19 dezembro 2019. URL : http://journals.openedition.org/ configuracoes/7620 ; DOI : 10.4000/configuracoes.7620 
Marques, Ana Paula; Chaves, Miguel; Serra, Helena; Urze, Paula - Introdução: Imaginar "futuros" do trabalho, contextos e vivências subjetivas. Configurações, vol. 24, 2019, pp. 5-10.

\title{
Introdução: Imaginar "futuros" do trabalho, contextos e vivências subjetivas
}

\author{
ANA PAULA MARQUES* \\ CICS-UMinho/ CICS-NOVA \\ MIGUEL CHAVES** \\ CICS-NOVA/ FCSH.UNL \\ HELENA SERRA*** \\ CICS-NOVA/ FCSH.UNL \\ PAULA URZE**** \\ FCT-UNL, CIUHCT
}

A urgência de respostas face à intensificação de crises económico-financeiras recorrentes tem conduzido a uma aceleração sem precedentes no domínio tecnológico, designada por Revolução 4.0. Por oposição à evolução gradual ou linear, típica das revoluções tecnológicas precedentes, a difusão da economia digital, em especial das plataformas digitais de trabalho, representa um enorme desafio pela sua intrínseca complexidade, imprevisibilidade e desmaterialização de processos, produtos, bens e serviços. Nada nem ninguém se encontra totalmente imune à redução do tempo de vida das tecnologias resultante da inovação constante. As transformações decorrentes dessa volatilidade tecnológica penetram todos os domínios da vida pública e privada (Schwab, 2018; Gerd, 2017; Beck, 2015). Mas, naturalmente, as mudanças com impacto na realidade laboral não se esgotam nas questões tecnológicas. Também os processos globais de mudança nos estilos de vida, estruturas e papéis familiares e educacionais afetam as organizações, os mercados de trabalho, os padrões de mobilidade profissional e o próprio potencial de empregabilidade de cada sociedade.

*E-mail: amarques@ics.uminho.pt

**E-mail: miguel.chaves@fcsh.unl.pt

*** E-mail: helena.serra@fcsh.unl.pt

$* * *$ E-mail: pcu@fct.unl.pt 
Igualmente, assiste-se ao refluxo da regulação estatal na economia e no trabalho e emprego, com repercussões na precarização dos trabalhadores e na crescente dessindicalização de amplas faixas da população, ainda que amenizado por movimentos sociais e instâncias de reivindicação, amplamente disseminados na internet e em redes virtuais diversas, cuja capacidade de intervenção ainda não é possível avaliar.

Ora, a crescente perda de privacidade, as controvérsias em torno do desemprego tecnológico ou a desqualificação humana, ainda que em curso, e, portanto, sem uma leitura óbvia, interpelam-nos a propósito dos modelos de aprendizagem que serão adotados em contexto empresarial e comunitário; sobre as competências que irão ser valorizadas no trabalho e nas profissões do futuro; acerca dos recursos cognitivos, emocionais e identitários que nelas serão requeridos.

Imaginar os "futuros" do trabalho (Marques, 2019) obriga-nos a ver de outra maneira a realidade, ainda herdeira de um quadro normativo regulador de relações de trabalho que tem destacado o "fim do trabalho" ou a impossibilidade de se ter "emprego para a vida". Para lá da adequação das teses que sustentam a aproximação do "fim do trabalho", e das polémicas que aquelas enfrentam, é consensual admitir-se as profundas metamorfoses que esta atividade regista, fruto das exigências de flexibilidade dos sistemas produtivos, a que se associam a polivalência e as práticas de desregulação e instabilidade dos mercados de trabalho. No âmbito ainda da crítica a um "futuro sem trabalho" importa também reatualizar a crítica à neutralidade tecnológica (Maurice, 1985), pela crença que se encontra visível na: i) aparente naturalização das opções organizacionais decorrentes da ideologia tecnocrática dominante; ii) na crescente subalternização do fator humano face ao racional tecnológico (burocracias digitais e hiper-tecnologização organizacional com resultados na intensificação do ritmo de trabalho); iii) na opacidade das desigualdades sociais decorrentes da crescente polarização e dualização da mão-de-obra, da segmentação do mercado de trabalho; e iv) na amputação de um conjunto de garantias sociais com reflexos na precarização de vastos segmentos da força laboral.

Qual será o lugar do trabalho no instável mundo contemporâneo? Que impactos sociais se podem esperar das tendências de precarização e mobilidade no emprego? O trabalho está a humanizar-se ou a desumanizar-se no contexto da economia digital? É possível (e desejável) manter as fronteiras entre as esferas da vida privada e profissional? A realidade laboral do mundo atual contribui para intensificar ou reduzir as desigualdades sociais?

Estas interrogações constituem o ponto de partida para a apresentação do presente número da Revista Configurações. Nele se oferece aos leitores um dossiê temático organizado a partir de um conjunto de textos que convergem direta ou indiretamente para o propósito de problematizar os "futuros" do trabalho, apresentando, alguns deles, resultados empíricos que desafiam esquemas 
interpretativos mais convencionais oriundos das ciências sociais. Sem o propósito de abarcar na totalidade uma questão tão complexa, os textos que integram este dossiê vão porém, em alguns casos, além do esperado, refletindo sobre a tecnologia enquanto questão social, cujo potencial transformador depende das opções económicas, políticas e simbólico-valorativas que caracterizam uma dada conjuntura histórico-social. Mas detenhamo-nos um pouco sobre o conteúdo dos diversos artigos.

Num primeiro texto de reflexão sociológica face às controvérsias teóricas, políticas ou até de "estados de alma” sobre o futuro do trabalho, Hermes Augusto Costa contrapõe "vozes" oriundas da academia de jovens, decorrente da experiência pedagógica no espaço europeu a propósito da celebração do centenário da Organização Internacional do Trabalho (OIT), e as perspetivas sindicais, enquanto objeto de investigação, teórico e empírico, privilegiado pelo autor. A literatura dominante nesta área e os múltiplos estudos realizados tendem a ressalvar tendências de destruição versus criação de empregos e profissões no futuro (WEF, 2018). Do lado dos jovens universitários destaca-se uma “visão propositiva e ousada" apoiada em temas vários que, em grande medida, confluem do impacto das mudanças tecnológicas, da digitalização da economia, das condições de dignificação do trabalho e do combate às várias assimetrias laborais. Da visão dos sindicalistas destaca-se um pendor mais pessimista sobre a realidade laboral e o futuro das profissões perante o desafio da tecnologia. Não obstante, uma faceta "mais otimista" manifesta-se, nomeadamente ao se destacar as potencialidades de dispositivos da era digital, tais como as plataformas online e redes sociais, que difundem, por exemplo, conteúdos e informações relevantes no domínio das relações de trabalho. Face ao futuro, permanece o "receio de que as máquinas tomem o lugar do ser humano", convergindo os interlocutores para a construção de compromissos regulatórios efetivos para um trabalho mais emancipatório.

No texto seguinte, da autoria de João Vasco Coelho, exploram-se representações e práticas de mobilidade profissional ao nível das empresas multilocalizadas, através da expatriação e gestão de quadros internacionais. O desafio da internacionalização impõe-se hoje cada vez mais às organizações para se manterem competitivas nos mercados globais. Para a sua concretização, além de outros recursos disponíveis da economia digital que "eliminam" fronteiras espaciais e temporais, muitas empresas têm vindo a adotar modelos de reengenharia organizacional e gestão empresarial, em particular por via da externalização da produção de bens e serviços, o que tem vindo a configurar oportunidades de criação de emprego em diferentes pontos do globo. Por sua vez, a expatriação que alimenta estas práticas de mobilidade de profissionais tende a apresentar-se como oportunidade de "ganhar mundo", de sair da "zona de conforto", viabilizada através de convites ou nomeações. Nesse sentido, tende a prevalecer um discurso otimista sobre as vantagens de tal experiência, ocultando o facto de, em muitas situações, essa opção surgir como resultado de constrangimentos. O texto salienta as interseções dos domínios organizacional e individual, não totalmente isentas de tensão, inerentes 
às "decisões de ir" ou de se ser expatriado. Apesar da prevalência de atribuições externas, o convite (a identificação direta pela chefia/cliente), trata-se, como nos diz o autor, de uma situação de prestação de trabalho específica, uma situação de e para escolhidos. Porém, tal oportunidade de diferenciação não se apresenta universal e inequívoca, já que algumas situações de constrangimento foram igualmente sinalizadas como, por exemplo, "rejeições de convites", "necessidades de contornar (em off) regras e critérios de escolha formalmente instituídos" ou "pedidos de ajuda" de CEOs da empresa".

Relacionado com as novas estratégias de recrutamento, o artigo de autoria de Manuel Pereira Soares, constitui um excelente exemplo de uma comunidade virtual particular - LinkedIn - como estratégia potencial na busca de emprego. Com efeito, no âmbito da digitalização da sociedade atual, as vantagens das redes sociais ao serviço do processo de recrutamento têm vindo a ser destacadas na literatura da especialidade, quer em si mesmas, quer em combinação com outros métodos e práticas de recrutamento. Partindo de um core teórico constituído pelos conceitos de laços fortes e fracos propostos por Granovetter, em articulação com a capacidade exponencial de se alargar os contactos pessoais, o autor faz um balanço crítico acerca das potencialidades reais deste tipo de rede social, chamando atenção que esta pode ou não potenciar o capital social relevante no processo de obtenção de um emprego. Apesar das limitações inerentes ao estudo em si, designadamente quanto à generalização das conclusões, o autor sustenta que os laços fracos constituídos sobretudo por colegas de trabalho e amigos, a partir dos quais se podem divulgar informações relevantes sobre oportunidades de emprego, não são por vezes eficazes na geração de capital social, ainda que esse potencial se encontre latente. Futuros estudos nesta área poderão proporcionar uma discussão mais alargada sobre as redes sociais enquanto espaços que configuram desiguais oportunidades que condicionam quer a oferta quer procura de trabalho, ou mesmo uma análise de processos de "fechamento"/monopólio de determinadas profissões e/ou carreiras.

Numa perspetiva de cariz histórico-sociológico, Cláudia Múrias aprofunda, através de um estudo de caso centrado na discriminação de mulheres de regiões rurais do Alto Minho, a persistência, na economia global, de desigualdades intergeracionais. Com um suporte empírico robusto, ancorado em 38 percursos biográficos de mulheres de diferentes faixas etárias e freguesias rurais de Viana de Castelo, operacionalizado através da realização de cinco focus group, a autora traça quatro marcos teórico-temporais na trajetória de inserção profissional da mulher rural. Da análise dos percursos biográficos por perfil geracional, conclui-se que as estratégias de conciliação dos papéis de "cuidadora" e "provedora da família", por parte das mulheres, através da participação no mercado de trabalho, têm sido acompanhadas pela constância, nos seus trajetos de vida, da orientação para a "domesticidade". Ora, face aos processos globais de mudança social, importa não esquecer a persistência de "velhas" 
discriminações que ganham espessura e enraizamento sociais, justamente por perpetuarem desiguais percursos de inserção no mundo do trabalho.

Também com o objetivo explícito de ensaiar pistas comuns de reflexão sobre trabalho e sexo, enquanto objetos de regulação, o artigo de Tiago Ribeiro desafia-nos a assumir uma postura aberta e crítica, com base nas premissas da relação entre "lógicas de mercadorização do trabalho e lógicas de psiquiatrização do sexo". As afinidades destes dois campos da ação humana, aparentemente díspares, estimulam o leitor a reconhecer e a refletir sobre os argumentos substantivos que perpassam o governo jurídico-laboral e sexual do sujeito nas sociedades contemporâneas. Tanto o trabalho como o sexo reivindicam questionamentos permanentes na relação entre desvio, normalidade e sentido, refletindo fronteiras, transgressões, resistências e a (re)invenção de categorias e de atributos simbólico-ideológicos. Na finalização do artigo, o autor exemplifica essa afinidade epistémico-funcional, referindo-se ao "governo da normalidade sócio laboral”, por via, por exemplo, da validação psiquiátrica do assédio como ilicitude laboral, ou da influência do "mercado no governo da normalidade sócio sexual”, por via da problemática do "índice gay” como dispositivo governamental. São portanto várias as pistas sugeridas para o desenvolvimento de futuras investigações sociológicas neste domínio, pesquisas que poderão simultaneamente contribuir para o questionamento das bases culturais do direito como fenómeno social.

Finaliza-se o dossiê temático com o contributo dos autores, Sílvia Gomes e Rui Vieira Cruz, que propõem uma discussão em torno das "tecnologias convergentes" (físicas, digitais e biológicas) e o seu potencial na transformação das conceções sobre o que é o crime, o criminoso e, consequentemente, que tipo de (controlo) organização social se pretende. Para isso, socorrem-se de um conjunto de episódios de uma série audiovisual de animação japonesa, Psycho-Pass, enquadrada no movimento (pós)cyberpunk, centrada no tema do combate ao crime num futuro distópico situado em 2112. Os autores combinam os contributos das teorias sociais do crime, em especial das que destacam a perspetiva do curso de vida na compreensão dos atos criminosos, para analisarem e interpretarem os conteúdos de narrativas, personagens e mecanismos de controlo e prevenção das infrações. A definição de crime e a atuação face às práticas criminais nesse futuro imaginado, no qual as tecnologias convergentes moldam as técnicas de controlo social e, consequentemente, o comportamento humano (via predictive thinking), não são totalmente imunes ao elemento humano, ainda que possam incorporar novos dispositivos, "em particular cyborgs e transumanos". Para os autores, há uma margem de humano, quando se consegue problematizar o sistema prescritivo e provocar a falha do mesmo, impossibilitando a predeterminação absoluta dos comportamentos antissociais. Esta nota otimista de resistência à desumanização num futuro em que as tecnologias convergem, reitera que o imprevisto, o acaso, a singularidade e a mutabilidade das trajetórias 
biográficas dos sujeitos são (inter)dependentes do tempo social e da organização social.

Não obstante a sua diversidade, os seis artigos que compõem o dossiê convergem num posicionamento crítico face a qualquer tendência homogeneizante e determinista da tecnologia - os "futuros" do trabalho implicam e dependem de heterodeterminações contextuais de múltiplas experiências subjetivas. Fica patente, igualmente, a urgência de investigações científicas que, privilegiando os interstícios das (inter)convergências de sistemas tecnológicos, organizacionais, profissionais e simbólico-valorativos, permitam imaginar e alicerçar escolhas de horizontes de futuro e de trabalho que se venham a revelar mais inclusivos, humanizados e coesos.

\section{Referências bibliográficas}

BECK, U. (2015), Sociedade de risco mundial. Em busca da segurança perdida, Lisboa, Edições 70.

GERD, L. (2017), Tecnologia versus Humanidade. O confronto futuro ente a Máquina e o Homem, Lisboa, Gradiva Editora.

MARQUES, A. P. (2019), Rev. 4.0. e competências. De que "futuros" de trabalho falamos?, Revista Formar \& Dirigir, Nº. 22, IEFP, pp. 32-35.

MAURICE, M. (1985), O determinismo tecnológico na sociologia do trabalho (1955-1990): uma alteração de paradigma?, D. Pimentel et al. (org.), Sociologia do Trabalho, Lisboa, A Regra do Jogo, pp. 231-254.

WORLD ECONOMIC FORUM (2018), The Future of Jobs. Report 2018, World Economic Forum (http://www3.weforum.org/docs/WEF_Future_of_Jobs_2018.pdf, acesso 20-02.2019). 